\title{
O PAPEL INDUTOR DA ADMINISTRAÇÃO PÚBLICA CONCERTADA NA EFETIVAÇÃO DOS DIREITOS HUMANOS PELAS EMPRESAS
}

\author{
Caroline Mendes Dias ${ }^{1}$ \\ Luciani Coimbra de Carvalho ${ }^{2}$
}

Resumo: As diretrizes contemporâneas no âmbito do sistema doméstico que tratam da relação direitos humanos e empresas, incluem o papel de fomento do Estado. Nesse contexto, o problema de pesquisa é analisar qual a responsabilidade do Estado como indutor da proteção dos direitos humanos em atividades empresariais, a partir da concepção da Administração Pública Concertada, com foco na cooperação, para a aplicação das diretrizes voluntárias, previstas no Decreto n. 9.571/2018 e Resolução CNDH n. 5/2020, que partem dos Princípios Orientadores das Nações Unidas, e ODS 8 e 12. Realizou-se pesquisa bibliográfica e documental, método dedutivo, enfoque descritivo e dogmático do Direito.

Palavras-chave: Responsabilidade do Estado Administração Concertada; Direitos Humanos; Atividade Empresarial; Diretrizes contemporâneas

\section{THE INDUCTIVE ROLE OF PUBLIC ADMINISTRATION CONCERTED IN THE EFFECTIVENESS OF HUMAN RIGHTS BY THE COMPANIES}

Abstract: Contemporary guidelines within the scope of the domestic system that deal with the relationship between human rights and companies include the role of promoting the State. The research problem is to analyze the State's responsibility as an inducer of the protection of human rights in business activities, based on the concept of Concerted Public Administration, with a focus on cooperation, for the application of voluntary guidelines, foreseen in Decree 9.571 and Resolution CNDH 5/2020, which depart from the United Nations Guiding Principles, and SDGs 8 and 12. Bibliographic and documentary research was made, deductive method.

Keywords: State Responsibility; Human Rights; Business Activity; Guidelines

\section{INTRODUÇÃO}

As atividades empresariais, embora sejam indispensáveis para o crescimento econômico, são potencialmente geradoras de violações aos direitos humanos, com impactos negativos de caráter socioambiental, antagonizando a perspectiva de desenvolvimento e do Estado de bem-estar social.

\footnotetext{
${ }^{1}$ Mestranda em Direito pelo Programa de Pós-Graduação em Direito da Universidade Federal de Mato Grosso do Sul (PPGD-UFMS). Advogada e Empresária (caroline@resinamarcon.com.br).

${ }^{2}$ Professora adjunta da UFMS na graduação e no Mestrado em Direito. Professora do Dinter em direito USP/UFMS. Doutora e Mestre em Direito do Estado pela PUC/SP. Advogada (lucianicoimbra@coimbraepalhano.com.br).
} 
Diante de tal potencialidade, vem crescendo a atenção à agenda de elo entre as atividades empresariais, os direitos humanos e a sustentabilidade, com iniciativa do Conselho de Direitos Humanos das Nações Unidas para os Princípios Orientadores sobre Empresas e Direitos Humanos (Princípios Ruggie), com reflexos na Agenda 2030, especialmente nos Objetivos de Desenvolvimento Sustentável n. 8 e 12, bem como na positivação do ordenamento jurídico brasileiro, com o Decreto n. 9.571/2018 e Resolução n. 5/2020 do Conselho Nacional dos Direitos Humanos.

Assim, a pesquisa se justifica pela relevância de analisar o papel e responsabilidade da administração púbica quanto às obrigações de proteção, fomento, monitoramento e divulgação para o cumprimento de normas e diretrizes de direitos humanos na gestão empresarial.

O problema de pesquisa é analisar qual a responsabilidade do Estado como indutor da proteção dos direitos humanos em atividades empresariais, a partir da concepção da Administração Pública Concertada, com foco na cooperação, para a aplicação das diretrizes voluntárias, previstas no Decreto n. 9.571/2018 e Resolução n. 5/2020 do Conselho Nacional dos Direitos Humanos

A metodologia utilizada empregou a pesquisa bibliográfica e documental, pelo método dedutivo, enfoque descritivo e dogmático do Direito.

\section{ESTADO DE DIREITO DEMOCRÁTICO SOCIAL E ADMINISTRAÇÃO CONCERTADA}

Atualmente a discussão sobre a autoridade do Estado converge para as relações entre os direitos fundamentais e a teoria democrática, que segundo Binenbojm (2008) são as duas maiores conquistas da moralidade política de todos os tempos. Da interdependência dos direitos fundamentais e democracia, surgiu o Estado democrático de direito, que tem como fundamento a proteção e promoção da dignidade da pessoa humana.

No processo conhecido por neoconstitucionalismo, concepção a partir da qual há o reconhecimento de que toda legislação infraconstitucional deve ser aplicada à luz da Constituição, tem-se que os sistemas democrático e de direitos fundamentais pulverizam seus 
efeitos conformadores por toda a ordem jurídico-política, condicionando seus institutos e estruturas (BINENBOJM, 2008).

As ideias de direitos fundamentais e democracia representam as duas maiores conquistas da moralidade política em todos os tempos. Não à toa, representando a expressão jurídico-política de valores basilares da civilização ocidental, como liberdade, igualdade e segurança, direitos fundamentais e democracia apresentam-se, simultaneamente, como fundamentos de legitimidade e elementos estruturantes do Estado democrático de direito. Assim, toda a discussão sobre o que é, para que serve e qual a origem da autoridade do Estado e do direito converge, na atualidade, para as relações entre a teoria dos di-reitos fundamentais e a teoria democrática (BINENBOJM, 2008, p. 49).

Assim, os movimentos que levaram à noção de estado contemporâneo tiveram como objeto a reavaliação dos fins do Estado e das funções típicas do modelo estatal providencialista e da forma como as funções do Estado eram comumente desempenhadas (OLIVEIRA, SCHWANKA, 2010).

Marçal Justen Filho (apud BINENBOJM, 2008) redefiniu o direito administrativo a partir dessa ótica dos direitos fundamentais, como o conjunto de normas que disciplinam as atividades administrativas necessárias à realização dos direitos fundamentais e organização das estruturas estatais e não estatais encarregadas de seu desempenho.

Os direitos fundamentais não se limitam mais ao ponto de vista dos indivíduos, mas de toda a sociedade, como bases estruturais da ordem jurídica, devendo o administrador público considera-los em seus processos de tomada de decisão e escolhas.

Bitencourt Neto (2017) afirma que as transformações operadas nas estruturas do Estado moderno implicam em novos desafios à Administração Pública, que passa a ter atuação como conformadora geral da ordem econômica e social, com atuação transversal e prospectiva, em busca de alcançar de forma mais efetiva, os objetivos centrais do Estado de Direito democrático e social.

Com a evolução do Estado Liberal de Direito para o Social de Direito, afluindo-se no hodierno Estado de Direito Democrático, houve a reformulação do Direito Administrativo, com a consequente mutação da Administração Pública, em suas mais diversas searas. É nesse contexto que o exercício da função administrativa deve ser aprimorado, objetivando garantir, sobremodo, o efetivo cumprimento dos direitos fundamentais dos homens e a proteção da dignidade da pessoa humana (MELLO, DANTAS, 2010, p. 2). 
As transformações que contextualizam a Administração Pública Contemporânea trazem como norte os fins sociais como vinculação à ação do Poder Público, posicionando-se entre os desafios da Administração do século XXI, a identificação de formas de realização do Estado Democrático e Social.

Superado o paradigma de uma Administração agressiva que marcou o período liberal do Estado de Direito, o Estado social levou, entre outras consequências marcantes, a intensa contratualização da atividade administrativa. Para além dos contratos em que figura como cliente dos particulares, abre-se para o Poder Público a senda da administração por acordos, ou dos contratos sobre o exercício de poderes públicos, compondo um amplo rol do que se pode chamar Administração concertada (BITENCOURT NETO, 2017, p. 12).

Nesse cenário do Estado Social de Direito e de implementação da reforma administrativa, torna-se imprescindível a característica da Administração Pública Contemporânea voltada à concertação, com adoção da consensualidade nas relações entre a sociedade e o Estado, com gestão focada em resultados, com maior eficiência.

Essa é a abordagem trazida por Mello e Dantas (2020, p. 2):

Assiste-se, pois, à passagem da Administração unilateral à Administração consensual, de modo a assegurar o pleno desenvolvimento das potencialidades individuais, bem como garantir maior eficiência na consecução do interesse público; há, portanto, maior inquietude e necessidade de conciliar a eficiência do agir estatal com a preservação dos direitos fundamentais da pessoa humana.

Segundo Bitencourt Neto (2019), a Administração concertada deve ser percebida em um contexto mais amplo, para além dos tradicionais contratos administrativos e privados, abarcando outros meios de consenso de feições menos definidas. A concertação administrativa abrange todo o extenso rol de tarefas administrativas, no âmbito da Administração interna e nas relações administrativas externas.

Oliveira (2008) traz a abordagem de que as posturas assumidas pelo estado mediador são distintas das posições tradicionalmente ostentadas pelo Estado impositor, cuja nota característica encontra-se justamente no poder de impor obrigações, exercido em razão do atributo da autoridade, imanente ao poder político ou estatal.

Aqui estaria presente a característica da Administração Concertada, linha de transformação do Direito Administrativo, onde o emprego da gestão consensual, é preferencial à atuação imperativa perante cidadãos, empresas e sociedade em geral. 
Dois exemplos desse fenômeno de concertação administrativa são impactantes: a) os contratos sobre o exercício de poderes públicos, que expressam um exercício contratualizado do poder de decisão unilateral da Administração Pública, quebrando o mito de que o poder de autoridade não se negocia; e b) os chamados "contratos internos", previstos, por exemplo, no art. 37, $\S 80$, da Constituição brasileira, além de diversos ordenamentos estrangeiros, como, por exemplo, o francês, o inglês e o português, que substituem a lógica de comando vertical por acordos entre órgãos despersonalizados, muitas vezes sustando os efeitos de relações hierárquicas em nome de uma maior eficácia na concretização das ações administrativas, pondo em xeque concepções tradicionais de uma personalidade jurídica unitária e monolítica do Estado (BITENCOURT NETO, 2017, p. 14).

Tratando da característica da Administração Concentrada e sua importância na contemporaneidade, Odete Medauar (apud Oliveira e Schwanka, 2009, p. 311) destaca:

A atividade de consenso-negociação entre Poder Público e particulares, mesmo informal, passa a assumir papel importante no processo de identificação de interesses públicos e privados, tutelados pela administração. esta não mais detém exclusividade no estabelecimento do interesse público; a discricionariedade se reduz, atenua-se a prática de imposição unilateral e autoritária de decisões. a administração volta-se para a coletividade, passando a conhecer melhor os problemas e aspirações da sociedade. [...] Daí decorre um novo modo de agir, não mais centrado sobre o ato como instrumento exclusivo de definição e atendimento do interesse público, mas como atividade aberta à colaboração dos indivíduos.

Pelo que se extrai, a referência na concepção de Administração Concertada é o diálogo entre administrador público e administrados, com foco na cooperação e participação da sociedade nas atividades até então tidas como exclusivas do Estado, tais como o fortalecimento dos direitos fundamentais, com colaboração ativa dos administrados, em um modelo de gestão aberta e democrática.

É diante de tal premissa que se desenvolve o presente estudo, analisando o papel do Estado e, via de consequência, da Administração Pública, na implementação e fortalecimento da proteção dos Direitos Humanos na atividade empresarial, considerando a dicotomia, à luz da Constituição de 1988 (BRASIL, 1988), dos pilares do Estado Democrático e Social, de que o desenvolvimento econômico nacional e o fortalecimento dos Direitos Humanos constituem objetivos fundamentais do país.

\section{VINCULAÇÃO DA ATIVIDADE EMPRESARIAL À PROMOÇÃO DE DIREITOS HUMANOS SOB A ÓTICA DOS MARCOS JURÍDICOS CONTEMPORÂNEOS}


No contexto do Estado Democrático e Social, fortalecido pelas expectativas recentes da sociedade, se fortalece um novo paradigma de responsabilidade social empresarial, pautada na prestação de contas de suas atividades à sociedade, destacando-se como um dos atores para a promoção dos direitos fundamentais.

Como contextualizado na Nota Técnica n. 7/2018 (PFDC, 2018):

Não obstante, a história brasileira e mundial revela que as atividades empresariais, embora sejam indispensáveis para o crescimento econômico, muito frequentemente geram inúmeros e igualmente grandiosos impactos negativos (por vezes irreversíveis) de caráter socioambiental e não raramente violações aos direitos humanos. Ou seja, ao invés da livre iniciativa e do desenvolvimento impulsionarem a afirmação do Estado de bem-estar social, eles terminam por antagonizar essa perspectiva (PFDC, 2018, p. 1).

Sen e Kliksberg (2010), apresentam que as ideias predominantes sobre o papel da empresa na sociedade se modificaram de forma acelerada nos últimos anos, evoluindo da visão preponderante durante décadas, de que a empresa possuía a responsabilidade apenas de geração de lucro a seus proprietários.

Na mesma linha, concluem Silveira e Almeida (2015, p. 370):

\begin{abstract}
A mudança das relações humanas e comerciais globais, que se tornaram deslocalizadas e desterritorializadas, alteraram os paradigmas mundiais de controle e da proteção dos direitos humanos inerentes ao ser humano.

Neste contexto, novas relações e tensões de poder surgem na sociedade economicamente globalizada entre Estados e Mercado. Assim, há um redirecionamento do papel da empresa em virtude das novas formas de violação dos direitos humanos nas relações transnacionais, ocasionadas pela imposição das regras mercadológicas para relativizar e, até mesmo, negar os direitos inerentes ao ser humano (trabalho, consumo, entre outros).
\end{abstract}

A visão de que o objetivo da atividade empresarial seria apenas a maximização de lucros foi destronada pela própria realidade, exigindo que as empresas saíssem do marco do narcisismo, surgindo a necessidade de ruptura paradigmática em relação às visões anteriores, passando às empresas que efetivamente respeitam os direitos humanos.

Contextualizando a proteção dos direitos humanos em relação às atividades empresariais, merece destaque o artigo 170 da Constituição brasileira (BRASIL, 1988), cujos termos impõem como princípios gerais da atividade econômica, a valorização do trabalho humano, a livre iniciativa, a função social, a defesa do meio ambiente e a redução das desigualdades regionais e sociais. 
As normas de proteção aos Direitos Humanos foram concebidas tendo como ator principal o Estado, considerado inicialmente como o único violador de tais direitos.

Tem-se então que ao passo que a Constituição Federal traga em seu bojo o princípio da livre iniciativa, como fundamento da ordem econômica, levando o Estado a estimular o desenvolvimento de atividades econômicas com intuito de lucro, o atual estágio de evolução social não permite que o processo empresarial sacrifique a dignidade humana, devendo ser premissa a efetivação de uma gestão socialmente responsável, que tenha como norte, paralelo ao lucro, o respeito aos Direitos Humanos, no âmbito social e ambiental.

Conforme registrado na Nota Técnica n. 7/2018 da Procuradoria Federal dos Direitos do Cidadão (PFDC, 2018), o objetivo de lucro impõe às administrações das empresas a pressão em minimizar custos e maximizar ganhos, comprimindo investimentos na proteção dos Direitos Humanos.

No plano internacional, conforme contextualizado por Silveira e Almeida (2015), desde o relatório de desenvolvimento humano global do ano de 2000 do Programa das Nações Unidas para o Desenvolvimento, se destacou a atenção especial à contribuição dos atores não estatais no fomento e proteção dos direitos fundamentais, na sociedade globalizada. Tal relatório trouxe a conclusão de que, nesse panorama, as empresas e associações privadas, passaram a ter maior impacto sobre a vida das pessoas e, portanto, o modelo de responsabilidade centrado no Estado deve ser ampliado para alcançar esses novos atores.

Nesse processo, em março de 2011, John Ruggie, designado pelo Secretário-Geral da ONU como representante especial na temática dos direitos humanos e empresas, o que, para Ramos (2018), se justificou em razão do tema apresentar controvérsias entre os que defendiam a expansão da interpretação das normas de direitos humanos para alcançar de maneira direta as empresas e aqueles que defendiam uma "colaboração" com as empresas, para a consolidação de uma "cidadania corporativa" mundial.

Como resultado dos trabalhos desenvolvidos, Ruggie apresentou um relatório final, acompanhado de princípios orientadores sobre o tema. Os Princípios de Ruggie, relativos às boas práticas empresariais, foram adotados pelo Conselho de Direitos Humanos da ONU por meio da Resolução 17/4. São 31 Princípios que representam contemporâneo instrumento de direitos humanos, embora não constituam um Tratado Internacional, por possuírem caráter de soft law. 
O Conselho de Direitos Humanos das Nações Unidas lidera duas iniciativas paralelas de reforço dos marcos normativos sobre direitos humanos e empresas. A primeira deu origem à criação do Grupo de Trabalho Empresas e Direitos Humanos (Working Group on Business and Human Rights), cujo mandato se refere à disseminação e implementação dos Princípios Orientadores sobre Empresas e Direitos Humanos, elaborados pelo Professor John Ruggie, por solicitação do Secretário-Geral das Nações Unidas e aprovados pelo Conselho de Direitos Humanos em 2011. A segunda diz respeito à proposição e discussão de um tratado internacional sobre o tema, atualmente em fase de discussão do primeiro rascunho (PFDC, 2018, p. 3).

Os pilares dos Princípios Ruggie agrupam-se em torno de: I. Dever do Estado de proteger os direitos humanos (princípios 1 a 10); II. Responsabilidade das empresas de respeitar os direitos humanos (princípios 11 a 24); III. Acesso a mecanismos de reparação (princípio 25 a 31 ).

\begin{abstract}
No contexto das atividades estimuladas pelo Grupo de Trabalho Direitos Humanos e Empresas da ONU, um dos temas centrais é a recomendação aos Estados para que adotem um Plano de Ação Nacional, definido como uma estratégia política evolutiva desenvolvida por um Estado para a proteção contra os impactos adversos em direitos humanos por empresas, em conformidade com os Princípios Orientadores sobre Empresas e Direitos Humanos (PFDC, 2018, p. 3).
\end{abstract}

Em resumo, os 31 "Princípios Ruggie" foram estruturados em três categorias: 1) Proteger: medidas de responsabilidade dos Estados; 2) Respeitar: medidas de responsabilidade das empresas; 3) Reparar: mecanismos a serem implementados pelos Estados e empresas.

Tais princípios influenciaram a Agenda 2030 da ONU, especificamente o ODS $n^{\circ}$ 8 (trabalho decente e crescimento econômico), ODS $\mathrm{n}^{\circ} 10$ (combate de desigualdades para que os seres humanos possam desfrutar de vida próspera e de plena realização pessoal e que o progresso econômico ocorra em harmonia com a natureza) e o ODS n ${ }^{\circ} 12$ (assegurar padrões de produção e consumo sustentáveis).

No contexto nacional contemporâneo, em 2018 houve inserção no ordenamento jurídico brasileiro do Decreto n. 9.571 que estabelece diretrizes nacionais sobre empresas e direitos humanos para médias e grandes empresas, incluídas as empresas multinacionais com atividades no País, estabelecendo que as microempresas e as empresas de pequeno porte poderão, na medida de suas capacidades, cumprir as Diretrizes de que trata referido Decreto, observado o disposto no artigo 179 da Constituição. 
$\mathrm{O}$ artigo $1^{\circ}, \S \S 2^{\circ}$ e $3^{\circ}$ do citado Decreto, dispõe que suas Diretrizes serão implementadas voluntariamente pelas empresas, sendo instituído o Selo "Empresa e Direitos Humanos", às empresas que voluntariamente as implementarem.

Conforme Netto Junior, Weichert e Nunes (2019), as disposições do Decreto n. 9.571/18 confrontam-se com a eficácia horizontal dos direitos fundamentais, uma vez que no sistema jurídico brasileiro, os direitos fundamentais devem não somente apresentar uma eficácia vertical, na relação do indivíduo com o Estado, mas também uma eficácia horizontal, verificada no âmbito das relações privadas, de modo que, evidentemente, sua observância cabe também aos atores privados.

Recentemente as diretrizes nacionais sobre direitos humanos e empresas foram reforçadas, com a publicação, em 12 de março de 2020, pelo Conselho Nacional dos Direitos Humanos - CNDH, da Resolução n. 5, que dispõe sobre os parâmetros para uma política pública voltada à matéria, tendo por base as disposições constitucionais, o ODS 8 da Agenda 2030, os Princípios de Ruggie, entre outras diretrizes nacionais e internacionais.

Para haver progresso na economia globalizada é necessária a sua construção sobre os pilares dos valores éticos e projetado ao futuro, incorporando um ideal coletivo, inclusivo para melhorar a vida das pessoas, "isto significa que não compete aos cidadãos adaptarem seus valores ao modelo da globalização, mas, sim, o modelo da globalização é que deve ser ajustado aos valores dos cidadãos" (BRANCO, apud SILVEIRA, ALMEIDA, 2015).

Em síntese, é necessária a análise dos Direitos Humanos à sua perspectiva econômica, pois se os indivíduos não puderem desfrutar de suas liberdades, a lógica dos mercados não se sustenta.

\section{PAPEL INDUTOR DO ESTADO PARA O FORTALECIMENTO DA RELAÇÃO DIREITOS HUMANOS E EMPRESA}

Diante do suposto antagonismo entre atividades empresariais e Direitos Humanos, a sociedade tem, cada vez mais, demandado o aperfeiçoamento dos instrumentos e marcos jurídicos para a proteção e promoção dos direitos humanos por parte das empresas (PFDC, 2018), bem como da atuação do Estado com relação à implementação de políticas para o fortalecimento de tal relação, o que se demonstra mais viável sob o aspecto da Administração 
Pública Concertada, especialmente diante do caráter não vinculativo - ao menos em análise superficial - dos marcos normativos contemporâneos.

Considerado como principal diretriz contemporânea sobre direitos humanos e empresa, os Princípios Ruggie, compostos por 31 princípios norteadores, são divididos em três categorias: "proteger", "respeitar" e "reparar".

Para se avaliar o papel indutor do Estado, com característica administrativa concertada, vale aqui registrar as categorias "proteger" e "reparar", que são direcionadas às atividades estatais, previstas nos princípios abaixo destacados (CONECTAS, 2012, p. 4-22):

\section{PRINCÍPIO 1}

Os Estados devem proteger contra violações dos direitos humanos cometidas em seu território e/ou sua jurisdição por terceiros, inclusive empresas. Para tanto, devem adotar as medidas apropriadas para prevenir, investigar, punir e reparar tais abusos por meio de políticas adequadas, legislação, regulação e submissão à justiça.

PRINCÍPIO 2

Os Estados devem estabelecer claramente a expectativa de que todas as empresas domiciliadas em seu território e/ou jurisdição respeitem os direitos humanos em todas suas operações.

PRINCÍPIO 3

Em cumprimento de sua obrigação de proteger, os Estados devem:

A. Fazer cumprir as leis que tenham por objeto ou por efeito fazer as empresas respeitarem os direitos humanos, avaliar periodicamente se tais leis resultam adequadas e remediar eventuais lacunas;

B. Assegurar que outras leis e diretrizes políticas que regem a criação e as atividades das empresas, como o direito empresarial, não restrinjam mas sim que propiciem o respeito aos direitos humanos pelas empresas;

C. Assessorar de maneira eficaz as empresas sobre como respeitar os direitos humanos em suas atividades;

D. Estimular e se for preciso exigir que as empresas informem como lidam com o impacto de suas atividades sobre os direitos humanos.

PRINCÍPIO 4

Os Estados devem adotar medidas adicionais de proteção contra as violações de direitos humanos cometidas por empresas de sua propriedade ou sob seu controle, ou que recebam significativos apoios e serviços de organismos estatais, tais como as agências oficiais de crédito à exportação e os organismos oficiais de seguros ou de garantia dos investimentos, exigindo, se for o caso, auditorias (due diligence) em matéria de direitos humanos.

PRINCÍPIO 5

Os Estados devem exercer uma supervisão adequada, a fim de cumprir suas obrigações internacionais de direitos humanos, quando contratam os serviços de empresas, ou promulgam normas com essa finalidade, que possam ter um impacto sobre o gozo dos direitos humanos.

PRINCÍPIO 6

Os Estados devem promover o respeito aos direitos humanos por parte das empresas com as quais realizam transações comerciais.

PRINCÍPIO 7

Tendo em vista que o risco de graves violações de direitos humanos é maior em regiões afetadas por conflitos, os Estados devem tratar de assegurar que as empresas 
que operem em tais contextos não se vejam implicadas em abusos dessa natureza, adotando entre outras as seguintes medidas:

A. Colaborar o mais cedo possível com as empresas para ajudá-las a identificar, prevenir e mitigar os riscos para os direitos humanos que impliquem suas atividades e relações empresariais;

B. Prestar assistência adequada às empresas para avaliar e tratar os principais riscos de abusos, prestando especial atenção tanto à violência de gênero quanto à violência sexual;

C. Negar o acesso ao apoio e serviços públicos a toda empresa que esteja envolvida em graves violações dos direitos humanos e se negue a cooperar para resolver a situação;

D. Assegurar a eficácia das políticas, leis, regulamentos e medidas coercitivas vigentes para prevenir o risco de que as empresas se vejam envolvidas em graves violações dos direitos humanos.

PRINCÍPIO 8

Os Estados devem assegurar que os departamentos e organismos governamentais e outras instituições estatais que orientem as práticas empresariais sejam conscientes das obrigações de direitos humanos do Estado e as respeitem no desempenho de seus respectivos mandatos, especialmente oferecendo-lhes informação, capacitação e apoio pertinentes.

PRINCÍPIO 9

Os Estados devem manter um marco normativo nacional adequado para assegurar o cumprimento de suas obrigações de direitos humanos quando firmem acordos políticos sobre atividades empresariais com outros Estados ou empresas, por exemplo, por meio de tratados ou contratos de investimento.

PRINCÍPIO 10

Os Estados quando atuem na qualidade de membros de instituições multilaterais que tratam questões relacionadas com as empresas, deverão:

A. Buscar assegurar que essas instituições não limitem a capacidade dos Estados membros de cumprir seu dever de proteção nem impeçam o respeito aos direitos humanos pelas empresas;

B. Incentivar essas instituições, no âmbito de seus respectivos mandatos e capacidades, a promover o respeito aos direitos humanos pelas empresas, e, quando demandadas, auxiliar os Estados no cumprimento de seu dever de proteção contra as violações dos direitos humanos cometidas por empresas, por meio de iniciativas de assistência técnica, atividades de formação e sensibilização;

C. Inspirar-se nestes Princípios Orientadores para promover o mútuo entendimento e a cooperação internacional no gerenciamento dos desafios relacionados às empresas e os direitos humanos.

PRINCÍPIO 25

Como parte de seu dever de proteção contra violações de direitos humanos relacionadas com atividades empresariais, os Estados devem tomar medidas apropriadas para garantir, pelas vias judiciais, administrativas, legislativas ou de outro meios que correspondam, que quando se produzam esse tipo de abusos em seu território e/ou jurisdição os afetados possam acessar mecanismos de reparação eficazes.

PRINCÍPIO 26

Os Estados devem adotar as medidas apropriadas para assegurar a eficácia dos mecanismos judiciais nacionais quando abordem as violações de direitos humanos relacionadas com empresas, especialmente considerando a forma de limitar os obstáculos jurídicos, práticos e de outras naturezas que possam conduzir para uma negação do acesso aos mecanismos de reparação.

PRINCÍPIO 27

Os Estados devem estabelecer mecanismos de denúncia extrajudiciais eficazes e apropriados, paralelamente aos mecanismos judiciais, como parte de um sistema estatal integral de reparação das violações de direitos humanos relacionadas com empresas. 


\section{PRINCÍPIO 28}

Os Estados devem contemplar formas de facilitar o acesso aos mecanismos nãoestatais de denúncia que tratam das violações de direitos humanos relacionadas com empresas.

Quanto à força normativa dos Princípios Ruggie, tem-se que constituem soft law, ou seja, não criam obrigações vinculante aos Estados. Apesar disso, devem incidir como eixo interpretativo na aplicação de normas nacionais e internacionais e, além disso, têm o potencial de eventualmente espelhar um costume internacional (RAMOS, 2018).

Internamente, o Estado brasileiro há muito desenvolve iniciativas para a indução do compromisso das empresas privadas com a temática de proteção e respeito aos Direitos Humanos, com destaque ao Programa Nacional de Direitos Humanos (PNDH-3), instituído em 2009; o Programa Nacional de Ações Afirmativas; o Decreto n 9.427/ 2018, além dos instrumentos mais recentes, já citados, Decreto n. 9.571/2018, Resolução CNDH n. 5/2020.

Silva e Moreira (2010) consideram que o Decreto n. 9.571/2018 se baseia na teoria da reputação, conclusão que advém do fato de não prever qualquer tipo de punição ou fomento para empresas que respeitem os direitos humanos e normas do Decreto. Tal voluntariedade leva a crer que o selo será utilizado como salvo conduto, ou ainda, servirão para conceder às empresas um título de comprometida com os direitos humanos, trazendo benefícios reputacionais.

Importante destacar, entre as diretrizes nacionais trazidas pelo Decreto $\mathrm{n}$. 9.571/2018, as que destacam o papel indutor do Estado quanto à gestão socialmente responsável e voltada ao fortalecimento de uma sociedade justa e igualitária:

Art. $2^{\circ}$ São eixos orientadores das Diretrizes Nacionais sobre Empresas e Direitos Humanos:

I - a obrigação do Estado com a proteção dos direitos humanos em atividades empresariais;

II - a responsabilidade das empresas com o respeito aos direitos humanos;

III - o acesso aos mecanismos de reparação e remediação para aqueles que, nesse âmbito, tenham seus direitos afetados; e

IV - a implementação, o monitoramento e a avaliação das Diretrizes.

Art. $3^{\circ}$ A responsabilidade do Estado com a proteção dos direitos humanos em atividades empresariais será pautada pelas seguintes diretrizes:

I - capacitação de servidores públicos sobre a temática de direitos humanos e empresas, com foco nas responsabilidades da administração pública e das empresas, de acordo com os Princípios Orientadores sobre Empresas e Direitos Humanos da Organização das Nações Unidas, principalmente ações de:

a) sensibilização e promoção da educação contínua dos recursos humanos da administração pública para o fortalecimento da cultura em direitos humanos; e 
b) capacitação dos recursos humanos da administração pública para o tratamento das violações aos direitos humanos em contexto empresarial, de seus riscos e de seus impactos;

II - fortalecimento da consonância entre políticas públicas e proteção dos direitos humanos;

III - aperfeiçoamento dos mecanismos de transparência e de participação social;

IV - implementação de políticas, normas e incentivos à conduta das empresas quanto aos direitos humanos, por meio de: [...]

$\mathrm{V}$ - prioridade de setores com alto potencial de impacto em direitos humanos, tais como os setores extrativo, de varejo e bens de consumo, de infraestrutura, químico e farmacêutico, entre outros;

VI - desenvolvimento de políticas públicas e realização de alterações no ordenamento jurídico, a fim de: [...]

VII - estímulo à adoção, por grandes empresas, de procedimentos adequados de dever de vigilância (due diligence) em direitos humanos;

VIII - orientação da incorporação dos direitos humanos à gestão de riscos de negócios e de parcerias que venha a estabelecer, de modo a subsidiar processos decisórios;

IX - criação de plataformas e fortalecimento de mecanismos de diálogo entre a administração pública, as empresas e a sociedade civil;

$X$ - integração dos direitos humanos ao investimento social, aos projetos de desenvolvimento sustentável para as comunidades impactadas e às políticas de patrocínio;

XI - garantia de condições de trabalho dignas para seus recursos humanos, por meio de ambiente produtivo, com remuneração adequada e em condições de liberdade, equidade e segurança, com estímulo à observância desse objetivo pelas empresas; Ver tópico

XII - combate à discriminação nas relações de trabalho e promoção da valorização da diversidade;

XIII - promoção e apoio às medidas de inclusão e de não discriminação, com criação de programas de incentivos para contratação de grupos vulneráveis;

XIV - estímulo à negociação permanente sobre as condições de trabalho e a resolução de conflitos, a fim de evitar litígios; Ver tópico

$\mathrm{XV}$ - aperfeiçoamento dos programas e das políticas públicas de combate ao trabalho infantil e ao trabalho análogo à escravidão;

XVI - estímulo à adoção de códigos de condutas em direitos humanos pelas empresas com as quais estabeleça negócios ou atue em parceria, com estímulo do respeito aos direitos humanos nas relações comerciais e de investimentos estatais; XVII - garantia de posição de negociação equilibrada com a empresa para os grupos em situação de vulnerabilidade, com garantia de suporte técnico e, sempre que possível, apoio da Defensoria Pública do Distrito Federal, dos Estados e da União;

XVIII - priorização de medidas para grupos em situação de vulnerabilidade e situações severas;

XIX - estímulo à criação de comitês permanentes para combate a desastres em contextos empresariais, o qual regulamentará questões sobre: [...]

XX - monitoramento da recuperação do território impactado por desastre a partir de indicadores capazes de aferir a reparação dos danos nos direitos humanos.

Parágrafo único. As denúncias de que trata a alínea d do inciso IV do caput serão tratadas por meio de fluxo de atendimento e de resposta públicos e no prazo estabelecido.

Art. 13. O Estado manterá mecanismos de denúncia e reparação judiciais e não judiciais existentes e seus obstáculos e lacunas legais, práticos e outros que possam dificultar o acesso aos mecanismos de reparação, de modo a produzir levantamento técnico sobre mecanismos estatais de reparação das violações de direitos humanos relacionadas com empresas, como: [...] 
Art. 14. Compete à administração pública incentivar que as empresas estabeleçam ou participem de mecanismos de denúncia e reparação efetivos e eficazes, que permitam propor reclamações e reparar violações dos direitos humanos relacionadas com atividades empresariais, com ênfase para: [...] (BRASIL, 2018).

Acerca do caráter de voluntariedade do citado Decreto, Netto Junior, Weichert e Nunes (2019, p. 10) asseveram que:

O Decreto insiste nesse tipo de "normatividade branda" e expressamente declara, como dito acima, que as diretrizes são voluntárias para as empresas, o que, por si só, expressa sua insuficiência para fazer face ao grave fenômeno das violações aos direitos humanos no Brasil por atos comissivos e omissivos de empresas. Em realidade, falta à figura jurídica do Decreto a força normativa para criar obrigações ou proibições, as quais, em homenagem ao princípio da legalidade, demandam lei em sentido estrito. Ademais, tampouco explicitou a esperada proibição de que o Estado e suas empresas mantenham relações comerciais, de investimento, de financiamento, diretas ou indiretas, inclusive mediante subcontratação e aquisição de bens ou serviços, com empresas ou pessoas que violem os direitos humanos.

Já a Resolução CNDH n. 5/20 igualmente de natureza voluntária, estabelece obrigações do Estado, quanto à proteção dos direitos humanos, e das empresas, quanto ao respeito, além de mecanismos de reparação, prevendo que os direitos humanos são universais, indivisíveis, inalienáveis e interdependentes e o Estado tem o dever de assegurar os instrumentos para sua aplicação.

A partir dos eixos orientadores dispostos na Resolução CNDH n. 5/20, tem-se que os direitos humanos devem ter supremacia sobre quaisquer acordos de natureza econômica, especialmente os instrumentos jurídicos de comércio e investimento, cabendo ao Estado as seguintes diretrizes (CONSELHO NACIONAL DOS DIREITOS HUMANOS, 2020, p. 1):

Art. $2^{\circ} \mathrm{O}$ Estado é responsável por promover, proteger, respeitar e aperfeiçoar os mecanismos de prevenção e reparação de Direitos Humanos violados no contexto de atividades empresariais, devendo adotar todas as medidas jurídicas e políticas necessárias para assegurar a responsabilidade civil, administrativa, trabalhista e criminal das empresas envolvidas em violação de Direitos Humanos;

$\S 1^{\circ} \mathrm{O}$ Estado deve assegurar o pleno acesso à justiça, em igualdade de condições, às pessoas e comunidades atingidas por violações de Direitos Humanos cometidas por empresas;

$\S 2^{\circ}$ A atuação do Estado deve ser orientada à solução pacífica e definitiva dos conflitos, primando pelo princípio da centralidade do sofrimento da vítima, que impõe a participação ativa das pessoas e comunidades atingidas na elaboração dos mecanismos de compensação e prevenção, com vistas a evitar que a violação ocorra novamente;

$\S 3^{\circ} \mathrm{O}$ critério de reconhecimento de pessoas atingidas por violações de Direitos Humanos obedecerá prioritariamente ao princípio da autodeclaração, podendo ser qualquer pessoa ou comunidade que apresentar indícios de dano, ou risco de dano, direta ou indiretamente pelas operações, produtos ou serviços de uma empresa, sendo vedada a delimitação dos atingidos pela empresa violadora; 
$\S 4^{\circ}$ Caso a empresa opere em mais de um Estado nacional ou faça parte, ou seja, controlada por um grupo empresarial que opere em mais de um Estado nacional, os atingidos e atingidas serão considerados em toda a sua cadeia produtiva;

$\S 5^{\circ} \mathrm{O}$ Estado deve assegurar a eficácia dos instrumentos legais para acesso à informação que sejam úteis à prevenção, apuração ou reparação de violações aos Direitos Humanos;

Art. $5^{\circ}$ São eixos orientadores das Diretrizes Nacionais sobre Direitos Humanos e Empresas:

I - a supremacia dos Direitos Humanos frente a quaisquer acordos de natureza econômica, de comércio, de serviços e de investimento;

II - a obrigação do Estado com a implementação de medidas de prevenção e reparação que coíbam violações de Direitos Humanos no exercício da atividade empresarial, assim como a obrigação de proteção aos Direitos Humanos, exigindo que as corporações respeitem esses mesmos direitos no exercício de suas funções, garantindo, ainda, mecanismos de reparação integral aos atingidos e atingidas em caso de ocorrência de violações de Direitos Humanos;

III - a obrigação das empresas de efetuarem medidas que coíbam violações de Direitos Humanos no exercício de suas atividades, abarcando toda a sua cadeia de produção, assim como a observância obrigatória de direitos e garantias fundamentais, previstos no ordenamento jurídico nacional e em tratados internacionais de proteção aos Direitos Humanos, colaborando, ainda, para o alcance por parte de atingidos e atingidas por violações de Direitos Humanos, ocorridos no desempenho de suas atividades, a uma reparação rápida e integral;

IV - o direito dos atingidos e atingidas à reparação integral pelas violações de Direitos Humanos cometidos por empresas, com observância do princípio da centralidade do sofrimento da vítima;

V - a implementação, o monitoramento e a avaliação periódica das Diretrizes;

Art. $7^{\circ} \mathrm{O}$ Estado tem a obrigação de legislar, respeitar, proteger e assegurar a fruição de Direitos Humanos no contexto das atividades empresariais, pautando sua atuação pelas seguintes diretrizes: [...]

Art. 10. Os órgãos estatais e instituições de justiça não podem se valer de qualquer acordo extrajudicial ou judicial com empresas que as exonerem de suas obrigações de indenizar e reparar integralmente pessoas e comunidades atingidas por suas operações.

Art. 11. As negociações eventualmente desenvolvidas perante instâncias do Poder Público que atuem ou venham a atuar no tratamento de violação de Direitos Humanos cometidos no contexto da atividade empresarial, seja na esfera extrajudicial, no bojo de um processo judicial ou em paralelo ao processo judicial, devem se orientar pela busca de soluções garantidoras de direitos humanos, haja vista a assimetria entre as partes envolvidas, devendo observar os ditames a seguir descritos: [...]

Os Estados devem adotar políticas públicas de efetivo reforço da proteção aos direitos humanos diante de atividades empresariais e, instituindo sistemas que limitem o poder das empresas no caminho da relativização dos direitos humanos, em favor da priorização do desenvolvimento econômico (PFDC, 2018).

Assim, a partir dos marcos contemporâneos, as obrigações dos Estados com relação aos Direitos Humanos, perpassam em respeitar, proteger e fomentar tais direitos 
contra violações cometidas por terceiros, entre eles as empresas privadas, cenário em que cabe atuar com papel indutor através de políticas pertinentes a criar ambientes favoráveis para que as empresas não só respeitem os direitos humanos, mas também se estimulem a atuar como agentes de sua promoção.

É nesse contexto que se torna precípuo reconhecer relação estreita entre a consensualidade e a participação administrativa. Não se pode olvidar que a evolução dos mecanismos de participação ocorreu de forma simultânea à evolução do fenômeno consensual, aqui apresentada na característica concertada da Administração Pública (MELLO e DANTAS, 2010).

A partir da visão da Administração concertada, o fortalecimento do papel das empresas perante os Direitos Humanos deve facilitar o intercâmbio das melhores práticas, indicando métodos adequados, como auditorias (due diligence), utilizando da proximidade entre Estado e empresa, que apresenta meios para induzir o cumprimento das políticas a respeito dos Direitos Humanos, especialmente com relação às empresas que recebam seu apoio ou sejam seus fornecedores.

É necessário que os contratos de prestação de serviços ou a legislação que habilite essa prestação especifiquem que o Estado espera que as empresas respeitem os direitos humanos. Os Estados devem se assegurar de sua capacidade de supervisionar efetivamente as atividades das empresas, em especial por meio de mecanismos adequados e independentes de supervisão e de prestação de contas (CONECTAS, 2012).

Além disso, os Estados devem considerar a possibilidade de adotar abordagens multilaterais para prevenir e enfrentar atos de violação aos Direitos Humanos, assim como para fomentar iniciativas coletivas eficazes, tais como acordos econômicos, contratos de investimento, oportunidades econômicas, incentivos tributários, e apoios mercadológicos, como benefícios em processos licitatórios e a adoção de Selos voltados à notoriedade pública das boas práticas, como o previsto no Decreto n. 9.571/2018, que representa diferencial competitivo e marketing positivo para as empresas privadas.

Como valoroso exemplo de tal norte, atuando com característica de Administração Consensual voltada à indução da relação entre Direitos Humanos e Empresas, vale citar a edição da Portaria n. 350/2019 do Ministério de Direitos Humanos, que institui o 
Código de Conduta e de Respeito aos Direitos Humanos para Fornecedores de Bens e de Serviços do Ministério dos Direitos Humanos.

A citada Portaria MDH n. 350/2018 tem como finalidade esclarecer o que esse Ministério considera como conduta minimamente ética, sustentável e respeitosa aos Direitos Humanos, esperada de todas as empresas com as quais firma parcerias e contratos, com base nos pilares dos Princípios Orientadores sobre Empresas e Direitos Humanos da ONU (Princípios Ruggie), se apresentando como instrumento apto na indução da adoção da gestão socialmente responsável, com cultura de ética, respeito e valorização da diversidade e igualdade de oportunidades.

Tal iniciativa tornou obrigatória, no âmbito do Ministério dos Direitos Humanos, a adoção dos princípios, diretrizes e responsabilidades contidos no Código de Conduta, por ocasião da publicação de editais, e a inclusão de cláusulas nos contratos, convênios e instrumentos congêneres, a fim de orientar empresas e entidades no cumprimento das exigências nele previstas, das quais se destaca:

Art. $1^{\circ}$ Instituir o Código de Conduta e de Respeito aos Direitos Humanos para Fornecedores de Bens e de Serviços do Ministério dos Direitos Humanos, conforme Anexo desta Portaria, com a finalidade de esclarecer o que o Ministério dos Direitos Humanos considera conduta ética, com ênfase no respeito aos Direitos Humanos, nas relações contratuais com empresas fornecedoras de serviços e produtos e com entidades que desenvolvem parcerias com esta Pasta.

Parágrafo único. O Código também abrange as empresas e entidades que eventualmente prestem serviços e forneçam bens às empresas contratadas e parceiros institucionais.

Art. $2^{\circ}$ É obrigatória a adoção dos princípios, diretrizes e responsabilidades contidos no Código por ocasião da publicação de editais, e a inclusão de cláusulas nos contratos, convênios e instrumentos congêneres, a fim de orientar empresas e entidades no cumprimento das exigências nele previstas.

$\S 1^{\circ}$ Cada instrumento contratual e de parceria preverá requisitos para a adoção do Código pelas empresas e parceiros, observadas as especificidades de cada uma delas, tais como porte, número de empregados ou colaboradores e capacidade organizativa. $\S 2^{\circ}$ Os contratos e termos de parceria exigirão a apresentação, com 90 (noventa) dias de antecedência da data de eventual prorrogação, de relatório por parte dos contratados e parceiros sobre a implementação do Código nas respectivas empresas ou entidades (MDH, 2018, p. 1).

Vê-se então que muito embora as diretrizes contemporâneas afetas à relação entre Direitos Humanos e empresas, possuam caráter voluntário e cuja efetividade chega a ser objeto de dúvidas, há iniciativas do Estado brasileiro no sentido de demonstrar que na realidade se trata de instrumentos que vão ao encontro do contexto atual da consensualidade do Estado e da característica da Administração Concertada, já representando considerável passo no atendimento das obrigações do Estado em seu papel de indução da gestão 
socialmente responsável, promovendo-se o fortalecimento de uma sociedade justa, democrática e igualitária, também a partir das relações privadas.

\section{CONCLUSÃO}

A história recente demonstra que toda atividade empresarial, seja qual for seu porte, se apresenta com potencialidade de gerar impactos positivos ou negativos na sociedade, especialmente quanto às agendas afetas aos Direitos Humanos, como resultado de seus próprios processos, bem como por ações das partes envolvidas, como sócios e colaboradores.

Diante de tal realidade, as diretrizes de proteção dos Direitos Humanos em relação às atividades empresariais avançaram nos últimos anos, orientadas pela percepção de que o Estado não é o único violador de tais direitos, tampouco deve ser o único responsável pela garantia de respeito a eles.

Algumas dessas iniciativas estabeleceram diretrizes sobre direitos humanos e empresas, com instrumentos para exercício do papel do Estado para o monitoramento e fomento para que as empresas alcancem papel de vetores de desenvolvimento econômico socialmente responsável.

Buscou-se neste artigo analisar a responsabilidade do Estado com a proteção dos direitos humanos em atividades empresariais, tendo como foco as obrigações de fomento, divulgação e monitoramento no cumprimento de normas e diretrizes dispostas nos marcos jurídicos contemporâneos, especialmente os Princípios Orientadores das Nações Unidas, ODS 8 e 12, Decreto n. 9.571/2018 e Resolução n. 5/2020 do Conselho Nacional dos Direitos Humanos.

A referência na concepção de Administração Concertada é o diálogo entre administrador público e administrados, com foco na cooperação e participação da sociedade nas atividades até então tidas como exclusivas do Estado, tais como o fortalecimento dos direitos fundamentais, com colaboração ativa dos administrados, em um modelo de gestão aberta e democrática.

A partir da visão da Administração concertada, o fortalecimento do papel das empresas perante os Direitos Humanos deve facilitar o intercâmbio das melhores práticas, indicando métodos adequados, como auditorias (due diligence), utilizando da proximidade 
entre Estado e empresa, que apresenta meios para induzir o cumprimento das políticas a respeito dos Direitos Humanos, especialmente com relação às empresas que recebam seu apoio ou sejam seus fornecedores.

O estudo alcançou sua proposta, concluindo que o suposto antagonismo entre empresas privadas, direitos humanos e Estado, requer a observância, pela administração pública, das diretrizes existentes para a promoção e proteção dos direitos humanos por parte das empresas.

Concluiu-se também que a atenção às expectativas sociais de gestão socialmente responsável, tem a potencialidade de ampliar a competitividade das empresas privadas, não só com a adoção interna de tais compromissos, mas também pela prestação de contas à sociedade, com o fim de demonstrar as boas práticas nesse sentido, gerando valor social no jogo do mercado e auferindo benefícios financeiros diretos com sua boa reputação, além da redução de riscos.

Por fim, é imprescindível que o Estado, aplicando as diretrizes da administração pública concertada, se movimente no sentido de implementar as diretrizes sobre direitos humanos e empresas, através de atividades de indução, educação e fomento, especialmente quanto à instituição do Selo "Empresa e Direitos Humanos", destinado às empresas que voluntariamente implementarem as Diretrizes de que trata o Decreto n. 9.571/2018, além de outras práticas, como criação de editais para capacitação, prêmios e linhas de créditos específicas para empresas que demonstrem cumprimento das diretrizes nacionais nesta matéria.

\section{REFERÊNCIAS}

BAUMAN, Zygmunt. A ética é possível num mundo de consumidores? Jorge Zahar Editor Ltda, 2013.

BRASIL. Constituição (1988). Constituição da República Federativa do Brasil. Brasília: Senado, 1988.

BRASIL. Decreto $\mathrm{n}^{\circ}$ 9.571, de 21 de novembro de 2018. Disponível em: https://presrepublica.jusbrasil.com.br/legislacao/649874325/decreto-9571-18. Acesso em 01 junho 2020. 
BINENBOJM, Gustavo. Uma Teoria do Direito Administrativo: Direitos Fundamentais, Democracia e Constitucionalização. Renovar. 2008.

BITENCOURT NETO, Eurico. Transformações do Estado e a Administração Pública no século XXI. Revista de Investigações Constitucionais, Curitiba, vol. 4, n. 1, p. 207-225, jan./abr. 2019.

BITENCOURT NETO, Eurico. Concertação Administrativa Iterorgânica: Direito Administrativo e Organização no Século XXI. São Paulo: Almedina, 2017.

CONECTAS DIREITOS HUMANOS. Empresas e direitos humanos. Parâmetros da ONU para proteger, respeitar e reparar. Relatório final de John Ruggie - Representante Especial do Secretário Geral. Disponível em: https://www.conectas.org/publicacoes/download/empresas-e-direitos-humanosparametros-da-onu. 2012. Acesso em: 25 maio 2020.

CONSELHO NACIONAL DOS DIREITOS HUMANOS. Resolução n. 5, de 12 de março de 2020. Disponível em: https://www.gov.br/mdh/pt-br/acesso-a-informacao/participacaosocial/conselho-nacional-de-direitos-humanos-cndh/copy_of_ResoluoDHeempresas.pdf. Acesso em: 25 maio 2020.

IENSUE, Geziela; CARVALHO, Luciani Coimbra de. Estado, Mercado e Direitos Humanos Fundametnais: um convite à reflexão da legitimidade a partir da política sobre a economia. Revista de Direito Brasileira. São Paulo. v. 18. n. 7. p. 63 - 81. Set./Dez. 2017.

MELLO, Shirlei Silmara de Freitas; DANTAS, Roziana G. Camilo Lemos. A lógica do consenso na administração pública contemporânea em face do paradigma do resultado. 2010. Disponível em: https://ambitojuridico.com.br/cadernos/direito-administrativo/alogica-do-consenso-na-administracao-publica-contemporanea-em-face-do-paradigma-doresultado/. Acesso em: 28 junho 2020.

MEZZAROBA, Orides; MONTEIRO, Cláudia Sevilha. Manual de metodologia da pesquisa no direito. 2. ed. São Paulo: Saraiva, 2004.

MINISTÉRIO DOS DIREITOS HUMANOS. Portaria n. 350, de 20 de novembro de 2018. Disponível em: www.in.gov.br/materia//asset_publisher/Kujrw0TZC2Mb/content/id/51057848/do1-2018-11-21-portaria-n-350de-20-de-novembro-de-2018-51057742. Acesso em 28 junho 2020.

NETTO JUNIOR, Edmundo Antonio Dias; WEICHERT, Marlon Alberto; NUNES, Raquel Portugal. A desconstrução do caráter vinculante das normas sobre empresas e direitos humanos: da natureza voluntária dos Princípios Ruggie à voluntariedade das diretrizes nacionais. Homa Publica - Revista Internacional de Direitos Humanos e Empresas. V. 3. Fevereiro-Julho 2019. p. 10-21.

OLIVEIRA, Gustavo Justino de Oliveira; SCHWANKA, Cristiane. A Administração Consensual como a nova face da Administração Pública no Séc. XXI: Fundamentos Dogmáticos, formas de expressão e instrumentos de ação. Revista da Faculdade de Direito 
da Universidade de São Paulo, v. 104, p. 303 - 322. Jan./dez. 2009. Disponível em: http://www.revistas.usp.br/rfdusp/article/view/67859/70467. Acesso em: 24 junho 2020.

PFDC. Nota Técnica n. ${ }^{\circ}$ 7/2018. A proteção e reparação de direitos humanos em relação a atividades empresariais. Brasília, DF, 2018.

RAMOS, André de Carvalho. Curso de Direitos Humanos. 5 ed. São Paulo: Saraiva, 2017.

SEN. Amartya. Desenvolvimento como Liberdade. São Paulo: Companhia das Letras, 2000.

SEN, Amartya; AJZEMBERG, Bernardo. As pessoas em primeiro lugar: A ética do desenvolvimento e os problemas do mundo globalizado. São Paulo: Companhia das Letras, 2010.

SILVA, Ricardo Murilo; MOREIRA, Felipe Oswaldo Guerreiro. Compliance para proteção dos direitos humanos em empresas. Homa Publica - Revista Internacional de Direitos Humanos e Empresas. V. 4. Janeiro-Dezembro 2020.

SILVEIRA, Vladmir Oliveira da; ALMEIDA, Patrícia Marinez. Empresas e Direitos Humanos. Revista Thesis Juris - São Paulo, V. 4, N. 2, p. 357-372, Maio-Agosto 2015.

SILVEIRA, Vladimir Oliveira; SANCHES Samyra Haydêe Dal Farra Naspolini. Direitos Humanos, empresa e desenvolvimento sustentável. 2015 Disponível em: https://doaj.org/article/4911110f284e4dfc9ec1f21755bb4dce. Acesso em 10 junho 2020.

SILVEIRA, Vladmir Oliveira da Silveira; ROCASOLANO Maria Mendez. Direitos Humanos: conceitos, significados e funções. São Paulo: Saraiva, 2010.

TAVARES, André Ramos. Curso de Direito Constitucional. 2. ed. São Paulo: Malheiros Editores, 2004. 